FEDERAL RESERVE BANK OF SAN FRANCISCO

WORKING PAPER SERIES

\title{
Beyond Kuznets: \\ Persistent Regional Inequality in China
}

\author{
Christopher Candelaria \\ Stanford University \\ Mary Daly \\ Federal Reserve Bank of San Francisco \\ Galina Hale \\ Federal Reserve Bank of San Francisco
}

November 2010

Working Paper 2009-07

http://www.frbsf.org/publications/economics/papers/2009/wp09-07bk.pdf

The views in this paper are solely the responsibility of the authors and should not be interpreted as reflecting the views of the Federal Reserve Bank of San Francisco or the Board of Governors of the Federal Reserve System. 


\title{
Beyond Kuznets: Persistent Regional Inequality in China
}

\author{
Christopher Candelaria \\ Stanford University \\ Mary Daly \\ Galina Hale*
}

Federal Reserve Bank of San Francisco

November 5, 2010

\begin{abstract}
Regional inequality in China appears to be persistent and even growing in the past two decades. We study potential offsetting factors and interprovincial migration to shed light on the sources of this persistence. We find that some of the inequality could be attributed to differences in quality of labor, industry composition, and geographical location of provinces. We also demonstrate that interprovincial migration, while driven in part by wage differences across provinces, does not offset these differences. Finally, we find that interprovincial redistribution did not help offset regional inequality during our sample period.
\end{abstract}

JEL classification: I3, J4, O5, R1

Key words: inequality, China

*Contact: Federal Reserve Bank of San Francisco, 101 Market St., MS1130, San Francisco, CA 94105. galina.b.hale@sf.frb.org. We thank Shang-Jin Wei for helpful suggestions. All errors are our own. The views in this paper are solely the responsibility of the authors and should not be interpreted as reflecting the views of the Board of Governors of the Federal Reserve System or any other person associated with the Federal Reserve System. 


\section{Introduction}

Persistent inequalities across regions are a feature of many developed and developing nations. This fact conflicts with standard neoclassical theory, which suggests that in a well-functioning economy regional inequalities should be eliminated through factor mobility, trade, or arbitrage. Although a significant research literature has been devoted to resolving the conflict between theory and fact, no real consensus has been formed (Magrini, 2007). In this paper, we analyze the patterns and causes of persistent regional inequality in China. Our findings contribute to the ongoing debate.

China presents a unique and important opportunity to study regional inequality. In terms of income, China is a very unequal country 11 According to World Bank estimates, China's income Gini coefficient far exceeds that of South Asian countries such as India, Bangladesh, and Pakistan. Income differences in China are large, both inter- and intraregionally, with interregional differences increasing over time (Fujita and Hu, 2001; Kanbur and Zhang, 1999). China is also a country in transition, altering its institutions and economy at a rapid pace but with considerable variation across provinces $2^{2}$ Moreover, the long history of regional separateness in China means that data collection efforts are as complete for China's provinces as they are for the country as a whole. Together these characteristics make China an ideal case study for examining the various hypotheses regarding persistent regional inequalities.

Hypotheses about regional inequalities fall into two broad categories. The first relates persistent inequalities to market imperfections associated with institutional or informational barriers that limit factor mobility, trade, or both (Magrini, 2007; Cremer and Pestieau, 2007) $\mathrm{S}^{3}$ Empirical work provides evidence for these types of barriers. For example, the cross-country research shows that persistent regional disparities can be linked to institutional barriers such as quotas on flows of human and physical capital, tariffs, and insufficient property rights. Studies within countries, where institutional barriers are less pronounced, find informational barriers to be important, especially those relating to the flow of labor across areas (Bound and Holzer, 2000). Again, China offers a

\footnotetext{
${ }^{1}$ Persistent and even growing cross-regional inequality in China during the reform period has been documented in the past (Jian, Sachs, and Warner, 1996).

${ }^{2}$ For a survey of regional inequalities in transition economies, see Huber (2006).

${ }^{3}$ Traditionally macro- and microeconomic approaches to this literature have focused on growth rates and levels, respectively. We focus on levels in this paper. For a review of the literature on growth rates see Magrini (2007).
} 
unique opportunity to study institutional barriers to labor migration because of a gradual removal of the system of permanent registration (hukou) during the time period we consider.

The second category of hypothesis on the causes of regional inequalities argues that persistent inequalities in income are not about constraints but are rather the result of unmeasured offsetting factors that work to equalize well-being across regional agents (Rice and Venables, 2003). Empirical work on this hypothesis has investigated differences in government tax and transfer programs, cost-of-living differences, and differences in amenities, but has not reached consensus (Rice and Venables, 2003).

In our sample we find, not surprisingly, that cost-of-living differences are, indeed, an important offsetting factor. Thus, we adjust average nominal wages in each province by a province-specific consumer price index (CPI) to obtain average real wages, which we use to study other offsetting factors. We consider measures of education levels in each province (to proxy for the quality of labor), industrial composition in each province, its geographical location, and cross-province government transfers. We take these factors one at a time and find that, with the exception of government transfers, they all help explain a substantial portion of wage differentials. These factors cannot all be considered together, because of the high correlation between the variables we consider in our sample. In the best case, about half of the variance in real wages across provinces remains after controlling for these offsetting factors.

There is a large body of research focused on inequality in China. For instance, Whalley and Zhang (2004) calibrate the effect of removal of the hukou system and show that its contribution to regional as well as urban-rural inequality is sizable. Kanbur and Zhang (2005) construct a long time series of regional inequality and show that it is explained, in different periods of time, by the shares of heavy industry, the degree of decentralization, and the degree of openness. In a recent paper, Wan, Lu, and Chen (2007) show that increasing globalization, uneven domestic capital accumulation, and privatization contribute to regional inequality in China, while the effects of location, urbanization, and the dependency ratio have been declining. Yao and Zhang (2001) demonstrate that there is divergence among groups (or clubs) of Chinese provinces in terms of real per capita GDP. Meng, Gregory, and Want (2005) argue that discontinued provision of free 
education, housing, and medical care as well as growing uncertainty increased the incidence of urban poverty when measured in terms of expenditure.

We find that cross-province migration to urban areas is driven, at least in part, by wage differentials; however, contrary to findings by Whalley and Zhang (2004), migration does not reduce wage inequality across provinces. We believe this is because between 1995 and 2000, a period for which we study migration, there were still restrictions on labor mobility that precluded labor flows from having any noticeable effect in terms of equalizing wages across provinces.

Our results indicate that regional inequality is likely to persist in China for quite some time, since it is due to such structural and long-term factors as education, industry composition, and geographical location. While further removing barriers to labor mobility may alleviate some of the regional wage differences, it is likely to be a slow process, because it needs to be accompanied by urban development. In the meantime, cross-province income redistribution may be useful to address social and economic tensions that regional inequality can bring. Our study finds that, in the period we consider, interprovince transfers did not help offset regional wage differences.

The paper is organized as follows: We begin by describing the policies that restrict labor movement in China in Section 2. We describe our data and recent trends in Section 3. In Section 4 we present the results of our empirical analysis. We conclude in Section 5.

\section{Migration policy in modern China}

In 1958, Mao Zedong set up a hereditary residency permit system, known as hukou, defining where people could work. This system classified individuals as either "rural" or "urban" workers and assigned them to a specific geographic area. Under this system, one cannot acquire a legal perma-

nent residence nor the numerous community-based rights, opportunities, benefits, and privileges in places other than where his hukou is. Only through proper authorization from the government can one permanently change his hukou location. For longer than a one-month stay and especially when seeking local employment, one must apply and be approved for a temporary residential permit. Violators are subject to fines, detention, and forced repatriation, which was partially relaxed in 
In addition to limiting the rural-to-urban migration of the workers, which explains an extraordinarily low degree of urbanization in China, this system limited migration across regions: migrants needed to obtain registration in the new area before they were allowed to work legally. Because of bureaucracy and red tape, obtaining registration could take months or years. Hence, the migration process in China was in many ways similar to the migration process across national borders.

Until 1978, the system was enforced rather strictly: police would periodically round up those without valid residence permits, place them in detention centers, and expel them from cities. After Chinese market reforms began 1978, a private sector appeared. Unlike state-owned enterprizes, private firms frequently do not require registration from potential employees. Economic reforms created pressures to encourage migration from the interior to the coast and provided incentives for officials not to enforce regulations on migration. However, even if migrants are hired without the registration, they do not have access to social services such as child care, schools, or health care.

Forced repatriation rules were still in place after the beginning of market reforms. In fact, the 1982 "Measures of Detaining and Repatriating Floating and Begging People in the Cities" streamlined the relevant legislation. It was not until 2003, after the tragic incident in Guangzhou, where a Hubei resident was beaten to death in jail in the process of repatriation, and the outcry that followed, that the repatriation law was relaxed. "Measures on Managing and Assisting Urban Homeless Beggars without Income" adopted on June 20, 2003, established new rules governing the handling and assisting of destitute migrants. Many cities, including the most controlled Beijing municipality, decided soon after that migrants outside their hukou must be dealt with more carefully; they are no longer automatically subject to detention, fines, or forced repatriation, unless they have become homeless, paupers, or criminals.

While recent reforms made it easier for migrants to survive without a hukou, they did not make it easier to obtain one. Thus, many people, especially those with families, are hesitant to permanently change their location. Moreover, fees charged for temporary residency permits, while fairly affordable, add to the cost of moving. Nevertheless, according to the census data, in 2000

\footnotetext{
${ }^{4}$ This information and some of what follows is taken in part from Wang (2005).
} 
almost 30 percent of the population was residing in a province other than the one in which they had their hukou.

There has been more progress in reforming the hukou system at the provincial level than at the national level. Between 2001 and 2007 a number of provinces adopted various measures, mostly addressing the rural-urban migration limitations. These measures ranged from changing the administration of the hukou system to completely abolishing the differences between rural and urban hukou 5

For the purpose of our project, we have to recognize that the barriers to cross-province migration in China still exist but weakened throughout our sample period. Moreover, we have to take into account the fact that the progress of reform was uneven across provinces.

\section{Data}

In this section, we describe our data sources for inequality, offsetting factors, and migration. We also describe recent trends and patterns in regional inequality and migration.

\subsection{Inequality and related data}

We use national and provincial level data that are reported in the China Statistical Yearbook. This annual publication is compiled by the National Bureau of Statistics of China and is published by the China Statistics Press. In conjunction with these data, we also use CEIC Data's "China Premium Database" because it provides time series of the data in the China Statistical Yearbook. Using these sources, we construct an annual data sample with a time range of 1993 to 2006, covering a period of fast economic growth in China. Due to data limitations, not all series have coverage for the entire period.

To measure income we use the average wage data. It is not reported separately for rural and urban households, however, the detailed description of the series (see Table A.1) suggests that most

\footnotetext{
${ }^{5}$ See "Recent Chinese Hukou Reforms" published by the Congressional Executive Commission on China, accessed at http://www.cecc.gov/pages/virtualAcad/Residency/hreform.php in October 2007.
} 
of the input into average wage comes from the urban wages.

Unlike most countries, China provides province by province consumer price index (CPI) data. We take advantage of this fact to calculate real wages using individual province CPI, which allows us to account for differences in cost of living in different provinces. Figure 1, which depicts the standard deviation of average wages across provinces as a measure of inequality, shows that because cost of living is higher in the provinces with higher average wage, part of measured inequality in average wage disappears once we account for the cost of living. For example, in 2006 the standard deviation of nominal wage across provinces was 31.3 , while the standard deviation of real wage was 23.7. Because real wage inequality and not nominal wage inequality is economically important, we conduct our analysis in terms of average real wage.

In the appendix, Table A.1 provides definitions and Table A.2 gives summary statistics for the variables we use in this paper. Because of the high level of economic growth in China, the variables are trending for all the provinces; thus, for measures of inequality, we express the majority of our variables in terms of percentage deviation from the country average. In doing so, we obtain unitfree, common trend-free, comparable variables for all the provinces. The variables that are not expressed in percentage deviation are CPI, berth capacity, inter-provincial migration, and rural-tourban intraprovincial migration.

In 1997, the city of Chongqing in Sichuan province was raised to the status of provincial city, resulting in creation of a new province and also affecting all the population-based statistics for the Sichuan province. Moreover, since Chongqing was the largest and wealthiest part of Sichuan, average income in the Sichuan province was also affected through a composition change. We take two approaches to dealing with Chongqing: we either drop Sichuan and Chongqing from our sample, or we construct weighted averages of variables for Chongqing and Sichuan after 1997. Measures of inequality are weighted by population except for CPI, which is weighted by GDP. In the rest of the paper, we present the results which treat Chongqing and Sichuan as a combined province, but our results do not change if we exclude both of them.

We omit the provinces of Hubei and Tibet from our data sample. We omit Hubei because of the vast relocation of residents there for construction of the Three Gorges dam beginning in December 
1994. We do not include Tibet because of a lack of a CPI index that extends back to 1993. Thus, we cannot construct real measures of key variables that are used in our analysis. With the omission of Hubei and Tibet, and the combination of Chongqing and Sichuan into a single province, we have a data set with a total of 28 provinces.

\subsection{Migration data}

We use migration data that is collected by the National Bureau of Statistics of China and compiled by China Data Online. The data we use come from the 2000 population census, which measures migration between November 1, 1995 and November 1, 2000. To our advantage, the data provide information not only on the province of origin and destination, but also the area within each province that the migrant came from and went to. This is especially useful to track patterns of migration such as the movement of people from rural to urban areas - both intra- and interprovincially 6

In the census, individuals five years of age or older were asked if, on November 1, 2000, they resided in a different subcounty-level unit than that in which they lived on November 1, 1995. If an individual moved his hukou to the new location or he resided in the new location for more than six months, he was counted as a migrant. While the migration data includes in-migration to Chinese provinces from Hong Kong, Macau, and abroad, we exclude these numbers from our analysis.

\subsection{Patterns in interprovince migration}

We now describe trends in the migration patterns in China. We focus on the migration that took place between 1995 and 2000, using information from the 2000 population census. Overall, there were 124.6 million migrants, approximately 9.9 percent of the total Chinese population in 2000. Of these, 91.8 million were intraprovincial migrants.

In our data, we have emigration (out-migration) from each province broken down into rural and urban migrants. The urban migrants are those coming from the subcounty-level units of neighborhood committee of the town and street. The rural migrants are the migrating population from townships and village committees of the town. With respect to immigration (in-migration),

\footnotetext{
${ }^{6}$ See Fan (2005) and Lavely (2001) for a detailed discussion of 2000 migration data.
} 
we are able to classify migrants as entering a town, city, or county. We broadly define city and town as an urban region and county as a rural region 7 Given the structure of the data, we are able to observe various patterns in migration patterns.

A large part of migration took place within provinces, with population moving from rural to urban areas. Of the intra-province migrating population, 35 percent moved from rural to urban areas during this time period 8 Inter-province migration was also important, with 76 percent of all inter-provincial migrants going into urban areas and almost none going to rural areas.

Table A.3. reports migration for all provinces between 1995 and 2000, both cross-province and rural-to-urban migration within the province, in levels and as a percent of host province population in 1997. Not surprisingly, the provincial cities of Beijing, Shanghai, and Tianjin attracted the most cross-province migrants as a share of their population. We also note that coastal provinces tended to attract more cross-province migrants as a share of their population than inland provinces. Trends in intraprovincial migration are more difficult to identify. The variance in rural-to-urban intraprovince migration across provinces is much smaller than that of the cross-province migration.

\section{What explains persistent interprovince inequality in China?}

In this section, we address two sets of explanations for persistent interprovince inequality discussed in the introduction. We begin by studying offsetting factors such as the quality of labor, industry composition, government transfers, and geographical factors. We then turn to the analysis of crossprovince migration patterns and test whether interprovince migration is driven, at least in part, by wage differences and whether this migration, in turn, helps offset some of these differences.

\subsection{Offsetting factors}

In this section, we look for reasons inequality may be persistent. We refer to them as "offsetting factors," although some of them in fact reflect imperfect measurement of remuneration for human

\footnotetext{
${ }^{7} \mathrm{Chan}$ and $\mathrm{Hu}$ (2003) include an appendix of major points in defining urban population for the 2000 census. In this appendix they state that the urban population of China consists of city and town population.

${ }^{8}$ Some of these numbers do not reflect actual moving of the population but the annex of rural areas by cities. For statistical purposes, however, this is identical to actual migration.
} 
capital. We begin with one such measure, education level. Since we do not have a direct measure of labor quality, we use two different measures of education levels in the province to proxy for the quality of labor. If observed differences in wages are fully explained by differences in labor quality, there is no reason to believe that such differences should go away. We then consider industry composition in the provinces. Because labor productivity may be higher in some industries, industry composition will affect the average wage in the province. While we would expect labor to move to the industries that are more productive, structural changes in the economy take a long time to complete and thus inequality that is caused by industry composition is expected to be persistent. Finally, we test whether some of the wage differentials across provinces are offset by transfers from the central government.

Results are reported in Table 19 The first two columns present our results with respect to measures of education level in each province. Column (1) uses as a proxy the number of college graduates per capita, while column (2) uses government expenditures on education (in real terms) per capita. We can see that both measures indicate that, indeed, higher levels of education are associated with higher average real wages. We can also see that the first measure explains 16.4 percent of standard deviation in real wages across provinces in 2006, while the second measure explains 54.4 percent ${ }^{10}$ although there could be some spurious correlation in the case of government expenses on education - provinces that are wealthy for whatever reason are likely to have higher wages and more expenditures on education. For this reason, and because of sample limitation in the case of the second measure, we use the first measure as a control variable in the tests that follow. Moreover, the first measure seems to be more relevant, because it measures the contemporaneous level of college education in the province.

Columns (3) through (6) of Table 1 use different measures of industrial composition - employment shares of primary, secondary, and tertiary industries, which correspond, respectively to mining and agriculture, manufacturing, and services. We find that all these measures explain some of the difference in real wages across provinces, with higher share of primary industry associated

\footnotetext{
${ }^{9}$ Because our right-hand side variables are highly correlated, we include them one at a time. See Table A.4. in the appendix for the correlation matrix.

${ }^{10}$ Note the sample difference between the two columns. They are due to the fact that education expenditure data are only available starting in 1999 .
} 
with lower average wage, while shares of secondary and tertiary industries (included one by one or together), are associated with higher average wage. Share of primary industries explains $53.5 \%$ of standard deviation in average real wage across provinces in 2006. We find these results intuitive, as manufacturing, and especially services, tend to employ more skilled labor and therefore have higher wages.

Column (7) shows the effect of the share of agricultural population in a province on its average wage. We find that real wage is lower in provinces with higher share of agricultural population. This effect reflects two factors - first is simply the fact that share of agricultural population is highly correlated with the share of primary industry; second is that in provinces with higher share of agricultural population there is more unskilled labor available and therefore there is likely to be downward pressure on unskilled wages and therefore on average wages ${ }^{11}$ This variable explains $35.4 \%$ of standard deviation in real wages across provinces.

In column (8) we include the berth capacity of the ports in the province, to proxy for access to export markets 12 Export industries tend to be more advanced technologically and are therefore likely to pay higher wages. We find that, indeed, higher berth capacity is associated with higher average real wage and explains $22.8 \%$ of standard deviation in average real wage across provinces in 2006.

Finally, column (9) of Table 1 uses the level of transfers from the central government to provinces, per capita, to test whether some of the wage differences are offset by government transfers across provinces. We find that, contrary to our expectations, the larger transfers go to the states with higher average real wages. Thus, government transfers, at least in the way we measure them, are not an offsetting factor during our sample period.

\footnotetext{
${ }^{11}$ Indeed, as we can see from tables A.5 and A.6 in the Appendix, higher share of agricultural population is associated with larger rural-to-urban migration.

${ }^{12}$ Our preliminary tests demonstrated that it is access to port rather than simply being on the coast that makes a difference (Candelaria, Daly, and Hale, 2009).
} 


\subsection{Labor mobility}

Before addressing the question of whether cross-province migration offsets some of the wage differences, we have to establish that cross-province migration is driven at least in part by wage differences. To this end, we test whether cross-province migration into urban areas between 1995 and 2000 is correlated with differences in real wages across provinces in 1995 (Table 2) and, alternatively, with differences in real wages in 1990 and differences in the growth rate of real wages between 1990 and 1995 (Table 3). In such a setup, migration does not affect wage differences ${ }^{13}$ We find that both the level and the growth rate of real wages have positive effects on migration into urban areas of a given province from other provinces ${ }^{14}$ These results hold even when we control for the offsetting factors that we found to be important in the first part of our analysis.

Coefficients on offsetting factors have expected signs — higher education and larger share of tertiary industries attract more migrants, while a higher share of agricultural population and higher share of primary industries lower the inflow of migrants. Interestingly, the share of secondary industries, while associated with higher wages (see Table 1), has a negative effect on migration, while tertiary industries seem to attract migrants. Berth capacity does not enter significantly in these regressions.

Having established that migration is indeed driven by wage differences, we now turn to the main question of interest - Does migration offset any of the wage differences? To this end, we estimate the effect of cross-province migration into urban areas between 1995 and 2000 on real wages in 2001, while controlling for our offsetting factors in 2001. The results are reported in Table 4 15

In column (1) we see that, far from offsetting wage differences, higher migration is associated with higher real wages. This effect is spurious, however. Because real wage differences across provinces are highly persistent over time, migration in 1995-2000 may be endogenous even with respect to 2001 real wages. To rule out this possibility, in column (2) we add the real wage in 1995 as an additional control variable. Once this control is included, migration no longer has a positive

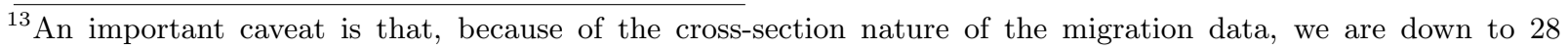
observations and a cross-province regression.

${ }^{14}$ For comparison, Tables A.5 and A.6 provide the same analysis for rural-to-urban migration within provinces.

${ }^{15}$ For comparison, results of similar tests for rural-to-urban migration within provinces are reported in Table A.7.
} 
effect on real wages. In fact, we find a negative effect in some specifications, which would indicate that there is some equalizing effect of migration, although this negative effect is never statistically significant and the reduction in the variance of the residual is minimal to nil (comparing column (2) with column (11)). We conclude, therefore, that the cross-province migration that occurred between 1995 and 2000 did not produce any equalizing effects.

\section{Conclusion}

Provincial statistics show that regional inequality in China has been persistent and even growing in the past two decades. We find that the main sources of this growth were structural and longterm factors such as labor quality, industrial composition, and geographical location. We find that interprovincial transfers did not offset wage inequality during our sample period, nor did interprovince migration. These findings suggest that regional income inequality in China is not likely to go away in the near future.

While we believe that fully removing barriers to labor mobility will help reduce cross-province wage inequality, we are aware that urban infrastructure is unable to accommodate large inflows of new migrants. We therefore view the message of this paper as more positive than normative given the gradual nature of structural changes and urban infrastructure development, we should expect regional inequality in China to persist for quite some time.

A policy implication of this observation is that social tensions that arise from such inequality may need to be addressed in the short run through redistribution. According to our analysis of the measures we considered, such redistribution has not been present during our sample period. The Chinese government, however, recognizes inequality as an important problem, which is reflected in its most recent five-year plan. 


\section{References}

Bound, J., And H. J. Holzer (2000): "Demand Shifts, Population Adjustments, and Labor Market Outcomes during the 1980s," Journal of Labor Economics, 18(1), 20-54.

Candelaria, C., M. Daly, and G. Hale (2009): "Interprovincial Inequality in China," FRBSF Economic Letter, 2009-13.

Chan, K. W., And Y. Hu (2003): "Urbanization in China in the 1990s: New Definition, Different Series, and Revised Trends," The China Review, 3(2), 49-71.

Cremer, H., and P. Pestieau (2007): "Factor Mobility and Redistribution," in Handbook of Regional and Urban Economics, vol. 4, pp. 2529-2560. Elsevier B.V.

FAN, C. C. (2005): "Interprovincial Migration, Population Redistribution, and Regional Development in China: 1990 and 2000 Census Comparisons," The Professional Geographer, 57(2), 295-311.

Fujita, M., AND D. Hu (2001): "Regional disparity in China 19851994: The effects of globalization and economic liberalization," The Annals of Regional Science, 35(1), 3-37.

Huber, P. (2006): "Regional Labor Market Developments in Transition," World Bank Policy Research Working Paper No. 3896.

JiAn, T., J. D. SAChs, And A. M. WARner (1996): "Trends in Regional Inequality in China," China Economic Review, 7(1), 1-21.

Kanbur, R., and X. Zhang (1999): "Which Regional Inequality? The Evolution of Rural-Urban and Inland-Coastal Inequality in China from 1983 to 1995," Journal of Comparative Economics, $27(4)$.

(2005): "Fifty Years of Regional Inequality in China: A Journey through Central Planning, Reform, and Openness," Review of Development Economics, 9(1), 87-106.

Lavely, W. (2001): "First Impressions from the 2000 Census of China," Population and Development Review, 27(4), 755-769. 
Magrini, S. (2007): "Regional (di)convergence," in Handbook of Regional and Urban Economics, vol. 4, pp. 2741-2796. Elsevier B.V.

Meng, X., R. Gregory, and Y. Want (2005): "Poverty, Inequality, and Growth in Urban China, 1986-2000," Journal of Comparative Economics, 33(4), 710-729.

Rice, P., And A. Venables (2003): "Equilibrium Regional Disparities: Theory and British Evidence," Regional Studies.

WAn, G., M. Lu, And Z. Chen (2007): "Globalization and Regional Income Inequality: Empirical Evidence from within China," The Review of Income and Wealth, 53(1), 35-59.

Wang, F.-L. (2005): "China's Household Registration (Hukou) System: Discrimination and Reform," Discussion paper, Congressional Statement, available at http://www.cecc.gov/pages/roundtables/090205/Wang.php.

Whalley, J., And S. Zhang (2004): "Inequality Change in China and (Hukou) Labour Mobility Restrictions," NBER Working Paper 10683.

YaO, S., And Z. Zhang (2001): "On Regional Inequality and Diverging Clubs: A Case Study of Contemporary China," Journal of Comparative Economics, 29(3), 466-484. 
Figure 1: Inequality in nominal and real wages

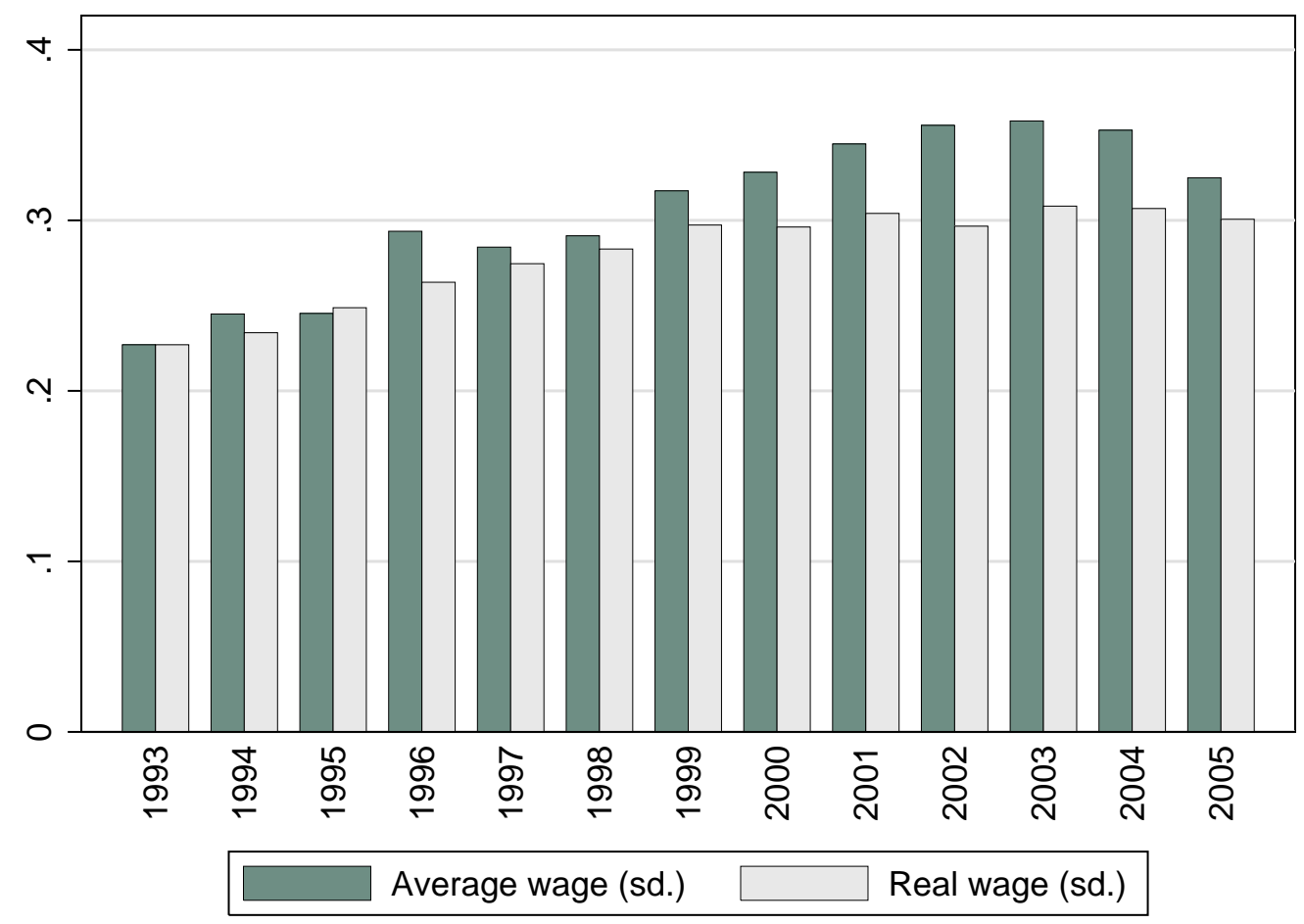

Source: CEIC China Database, authors' calculations. 


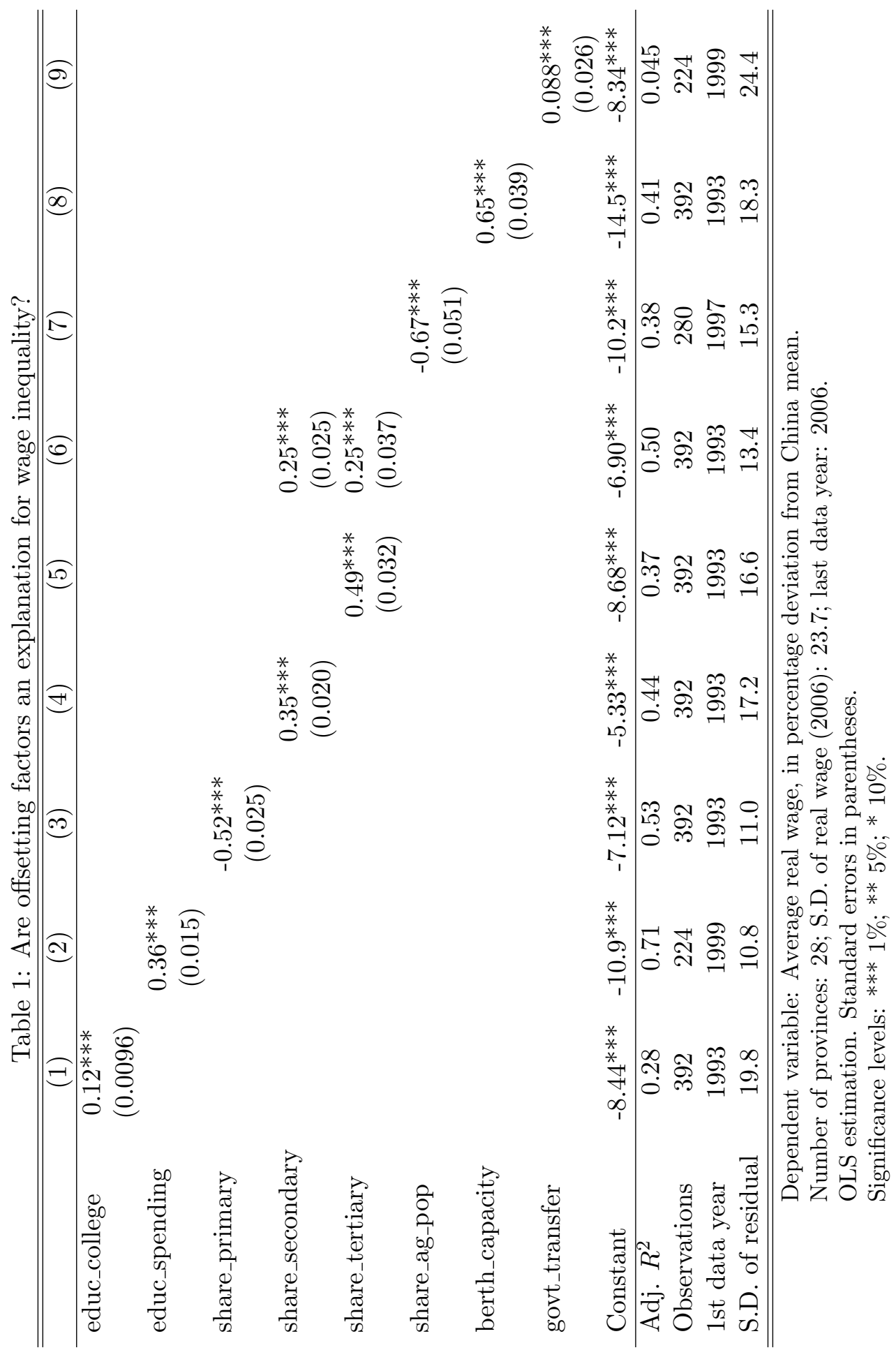









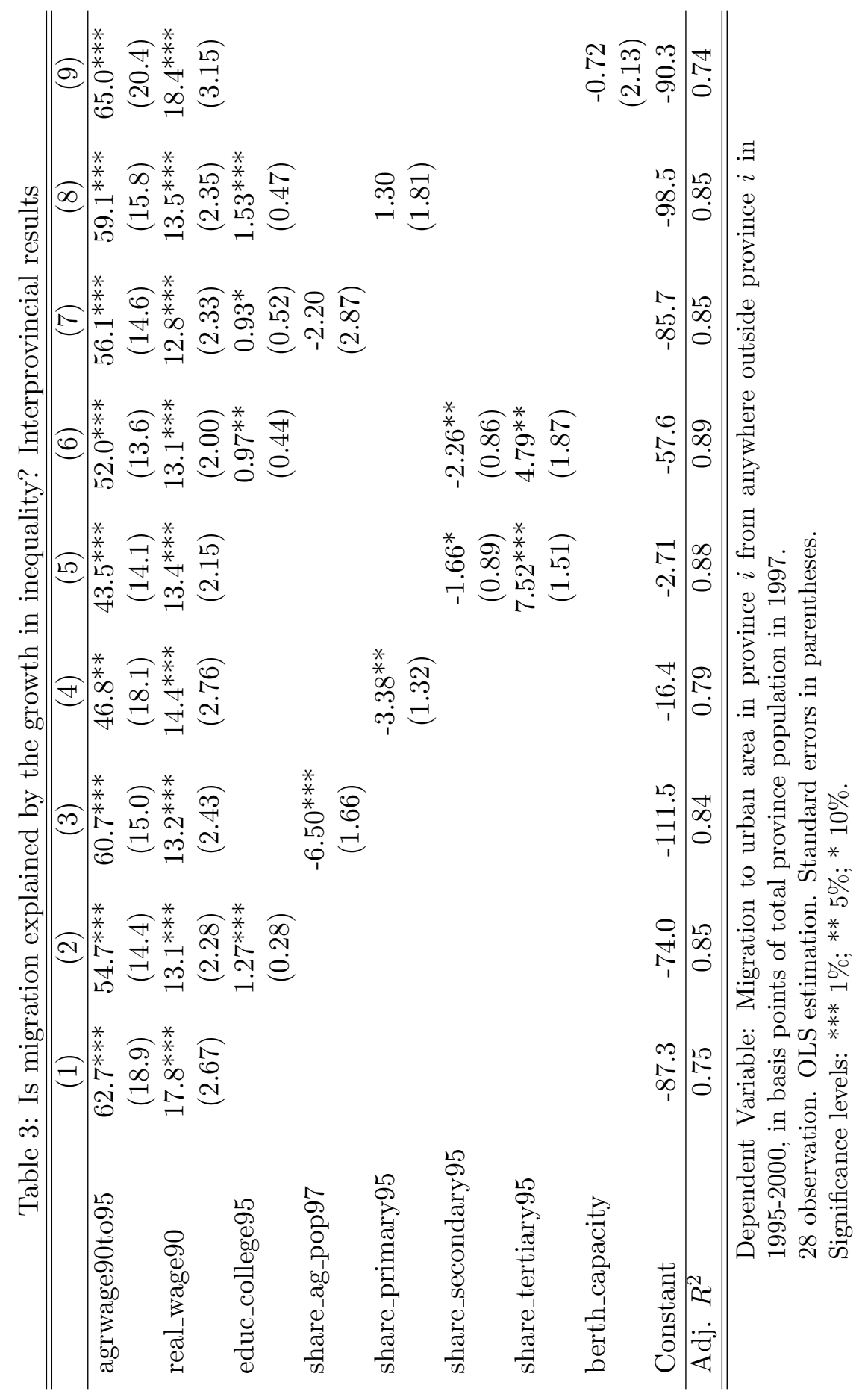




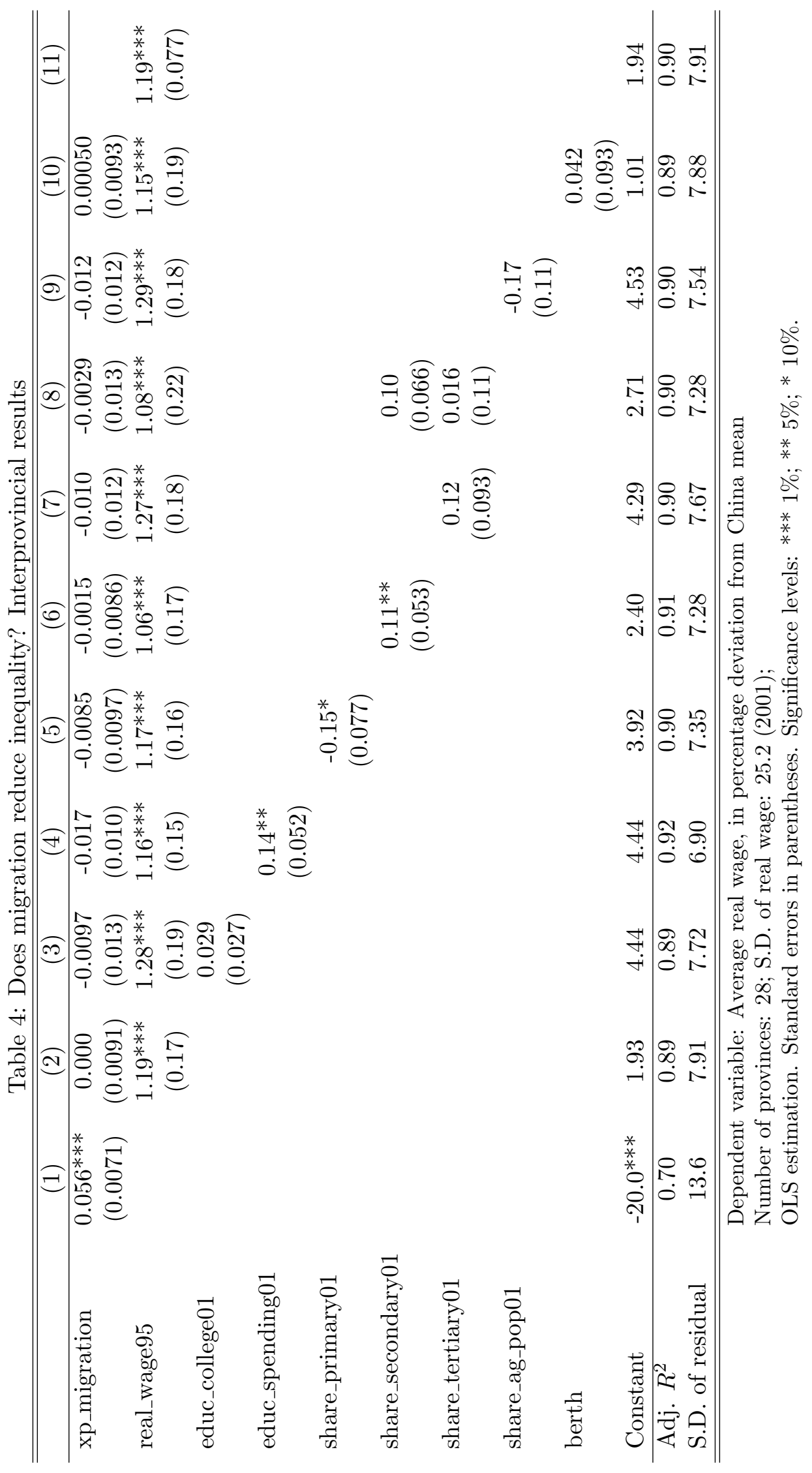




\section{A Appendix}

\section{Table A.1: Variable Definitions}

nominal_wage Average annual wage in yuan per person for staff and workers in enterprises, institutions, and government agencies, which reflects the general level of wage income.

cpi Consumer price index; $1988=100$.

real_wage Average annual wage in yuan per person for staff and workers in enterprises, institutions, and government agencies deflated by the consumer price index $(1988=100)$.

educ_college Number of college graduates of regular institutions of higher learning scaled by population.

educ_spending Expenditure of provincial government on education scaled by population.

share_primary Share of employees involved in the production of raw goods (primary sector).

share_secondary Share of employees involved in the manufacture of goods (secondary sector).

share_tertiary Share of employees in the services sector (tertiary sector).

share_ag_pop Share of agricultural population.

berth_capacity Number of berths in major coastal ports (10,000 ton class, end of year 2000).

govt_transfer National government subsidy to provincial government per capita.

xp_migration Number of migrants moving into an urban area of a province from an urban or rural area in another province. This variable is scaled by population in 1997 in the destination province (in basis points).

ru_migration Number of migrants moving into an urban area of a given province from a rural area in that province. This variable is scaled by the population in 1997 in the province (in basis points). 
Table A.2: Summary Statistics

\begin{tabular}{lccccc}
\hline \hline Name & 1st year data & Mean (level) & Std. Dev.(level) & Mean (PD) & Std. Dev (PD) \\
\hline nominal_wage & 1993 & 10491.9 & 6483.7 & 1.95 & 30.3 \\
cpi & 1993 & 249.7 & 37.1 & - & - \\
real_wage & 1993 & 3950.4 & 2005.6 & -5.93 & 22.7 \\
educ_college & 1993 & 0.001 & .001 & 18.5 & 99.9 \\
educ_spending & 1999 & 77.1 & 52.9 & 12.5 & 56.0 \\
share_primary & 1993 & 0.49 & 0.16 & -0.67 & 32.1 \\
share_secondary & 1993 & 0.22 & 0.10 & -4.1 & 43.8 \\
share_tertiary & 1993 & 0.29 & 0.08 & 4.7 & 28.1 \\
share_ag_pop & 1997 & 0.68 & 0.16 & -5.3 & 22.0 \\
berth_capacity & 1993 & 12.8 & 22.2 & - & - \\
govt_transfer & 1999 & 303.6 & 177.5 & 21.9 & 60.3 \\
xp_migration & 1993 & 0.26 & 0.36 & - & - \\
ru_migration & 1993 & 0.24 & 0.10 & - & - \\
\hline \hline
\end{tabular}

See Table A.1. for variable definitions.

$\mathrm{PD}$ is percent deviation from country average in each year. 
Table A.3: Migration Statistics: Cross-Province and Intraprovince

\begin{tabular}{|c|c|c|c|c|}
\hline & \multicolumn{2}{|c|}{$\begin{array}{c}\text { Cross-Province } \\
\text { In-migration to urban area }\end{array}$} & \multicolumn{2}{|c|}{$\begin{array}{c}\text { Intraprovince } \\
\text { In-migration to urban area from rural area }\end{array}$} \\
\hline & $\begin{array}{l}\text { Gross number } \\
\text { (thousands) }\end{array}$ & $\begin{array}{l}\text { Share province pop } \\
\text { (basis points) }\end{array}$ & $\begin{array}{l}\text { Gross Number } \\
\text { (thousands) }\end{array}$ & $\begin{array}{l}\text { Share province pop } \\
\text { (basis points) }\end{array}$ \\
\hline Anhui & 174 & .028 & 1143 & .19 \\
\hline Beijing & 1592 & 1.3 & 227 & .18 \\
\hline Chongqing/Sichuan & 448 & .039 & 3031 & .26 \\
\hline Fujian & 905 & .28 & 1413 & .43 \\
\hline Gansu & 182 & .073 & 468 & .19 \\
\hline Guangdong & 8534 & 1.2 & 3863 & .55 \\
\hline Guangxi & 236 & .051 & 1116 & .24 \\
\hline Guizhou & 202 & .056 & 681 & .19 \\
\hline Hainan & 183 & .25 & 191 & .26 \\
\hline Hebei & 497 & .076 & 1415 & .22 \\
\hline Heilongjiang & 238 & .063 & 613 & .16 \\
\hline Henan & 326 & .035 & 1576 & .17 \\
\hline Hunan & 273 & .042 & 1429 & .22 \\
\hline Inner Mongolia & 228 & .098 & 797 & .34 \\
\hline Jiangsu & 1265 & .18 & 2168 & .3 \\
\hline Jiangxi & 163 & .039 & 922 & .22 \\
\hline Jilin & 206 & .079 & 413 & .16 \\
\hline Liaoning & 600 & .14 & 742 & .18 \\
\hline Ningxia & 76 & .14 & 141 & .27 \\
\hline Qinghai & 70 & .14 & 90 & .18 \\
\hline Shaanxi & 366 & .1 & 714 & .2 \\
\hline Shandong & 667 & .076 & 2860 & .33 \\
\hline Shanghai & 1947 & 1.3 & 344 & .24 \\
\hline Shanxi & 225 & .072 & 734 & .23 \\
\hline Tianjin & 442 & .46 & 148 & .16 \\
\hline Xinjiang & 551 & .32 & 324 & .19 \\
\hline Yunnan & 627 & .15 & 1042 & .25 \\
\hline Zhejiang & 1892 & .43 & 2236 & .5 \\
\hline
\end{tabular}




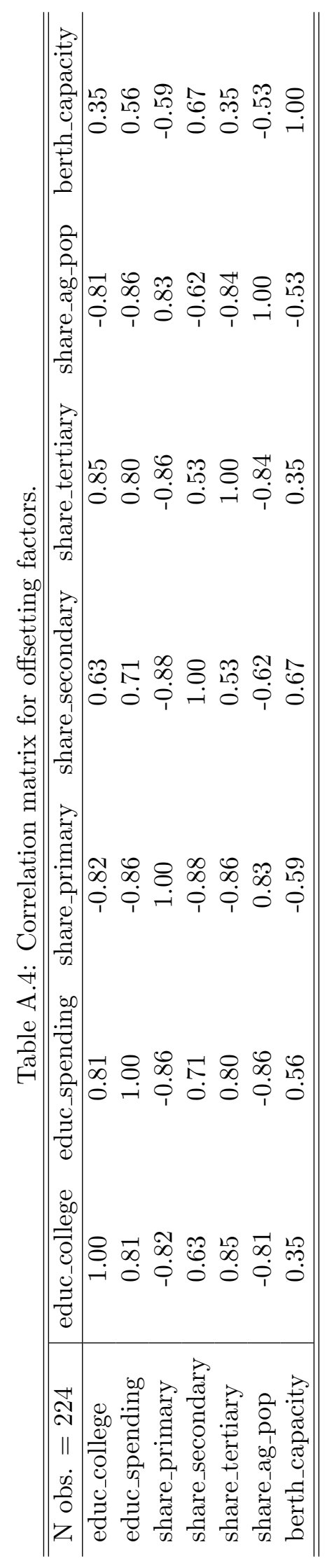




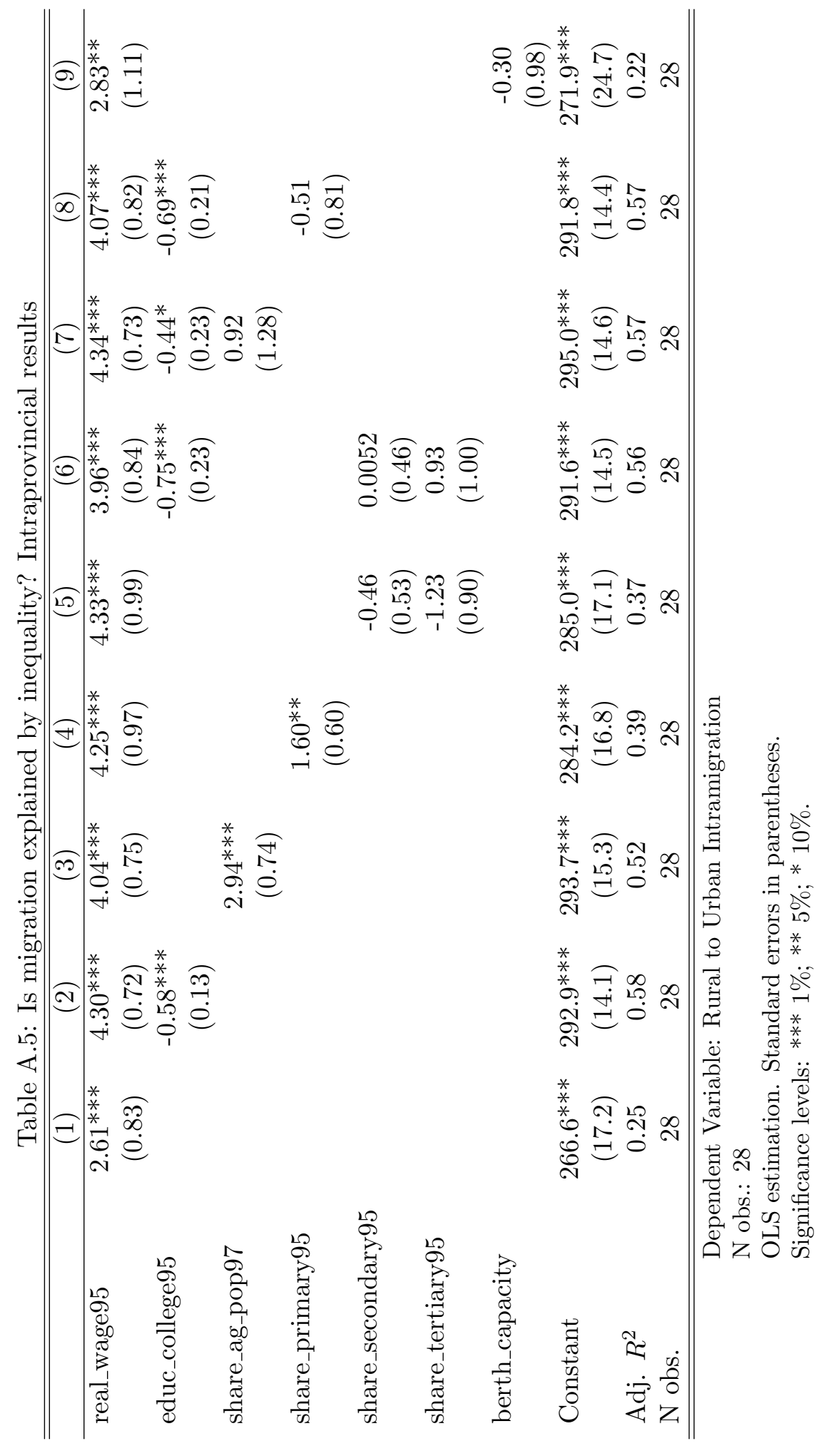




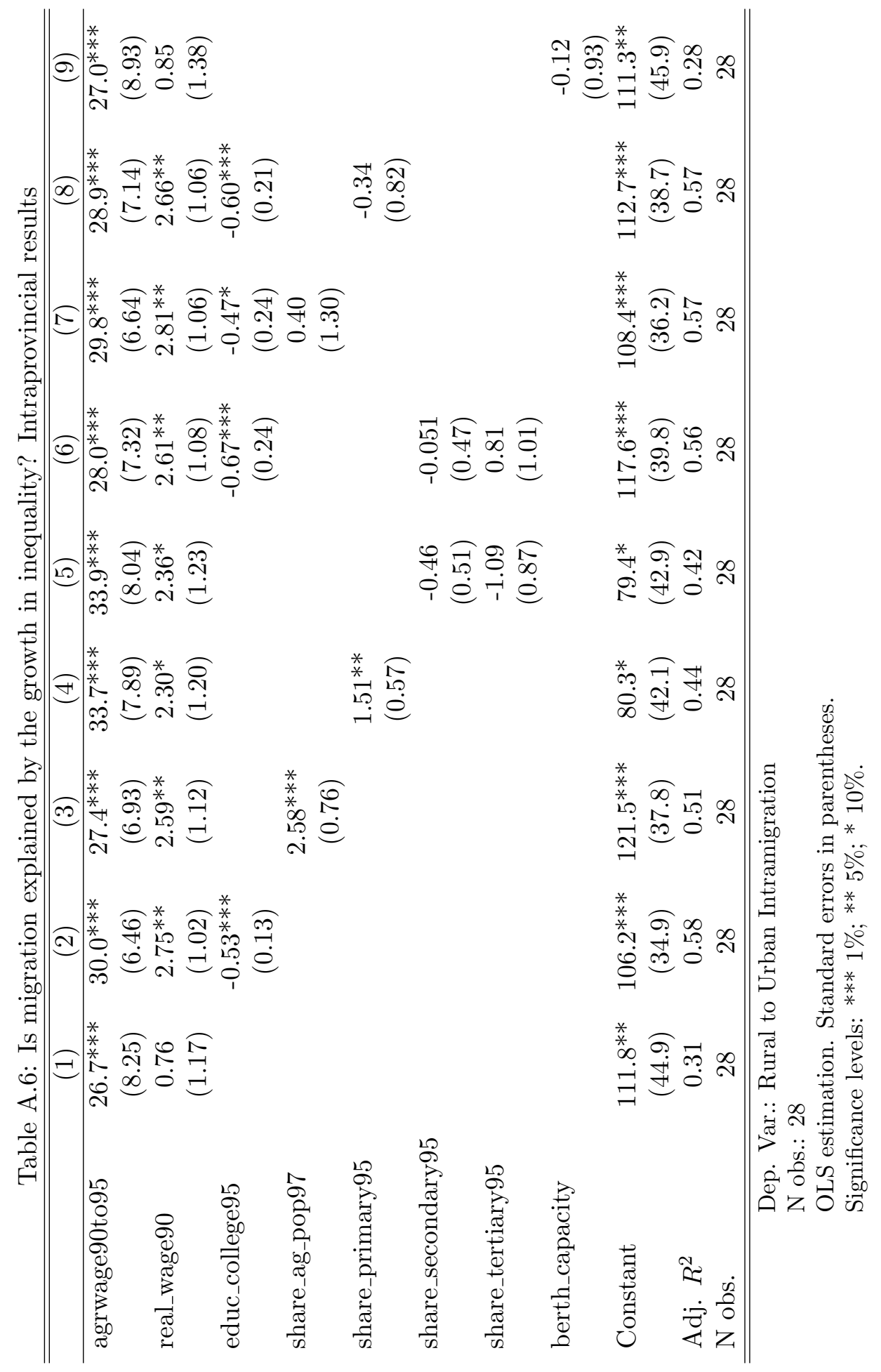




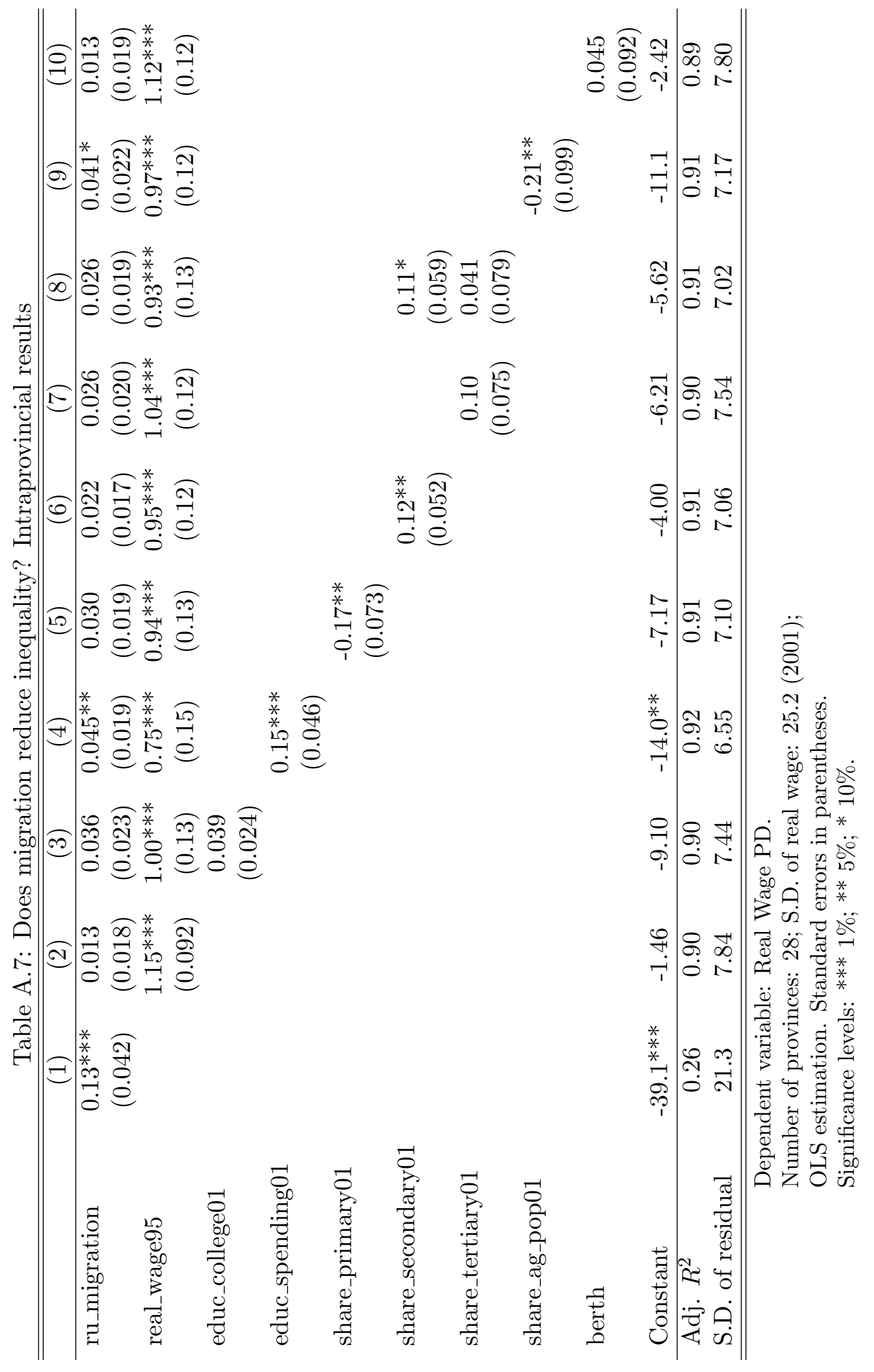

